\title{
Stimulation of the Noradrenergic System during Memory Formation Impairs Extinction Learning but not the Disruption of Reconsolidation
}

\author{
Marieke Soeter' and Merel Kindt*,' \\ 'Department of Clinical Psychology, University of Amsterdam, Amsterdam, The Netherlands
}

\begin{abstract}
The noradrenergic system plays a critical role in the 'consolidation' of emotional memory. If we are to target 'reconsolidation' in patients with anxiety disorders, the noradrenergic strengthening of fear memory should not impair the disruption of reconsolidation. In Experiment I, we addressed this issue using a differential fear conditioning procedure allowing selective reactivation of one of two fear associations. First, we strengthened fear memory by administering an $\alpha_{2}$-adrenergic receptor antagonist (ie, yohimbine $\mathrm{HCl}$; double-blind placebo-controlled study) 30 min before acquisition (time for peak value yohimbine $\mathrm{HCl}<\mathrm{Ih}$ ). Next, the reconsolidation of one of the fear associations was manipulated by administering a $\beta$-adrenergic receptor antagonist (ie, propranolol $\mathrm{HCl}$ ) 90 min before its selective reactivation (time for peak value propranolol $\mathrm{HCl}<2 \mathrm{~h}$ ). In Experiment II, we administered propranolol $\mathrm{HCl}$ after reactivation of the memory to rule out a possible effect of the pharmacological manipulation on the memory retrieval itself. The excessive release of noradrenaline during memory formation not only delayed the process of extinction $48 \mathrm{~h}$ later, but also triggered broader fear generalization. Yet, the $\beta$-adrenergic receptor blocker during reconsolidation selectively 'neutralized' the fear-arousing aspects of the noradrenergic-strengthened memory and undermined the generalization of fear. We observed a similar reduction in fear responding when propranolol $\mathrm{HCl}$ was administered after reactivation of the memory. The present findings demonstrate the involvement of noradrenergic modulation in the formation as well as generalization of human fear memory. Given that the noradrenergic strengthening of fear memory impaired extinction learning but not the disruption of reconsolidation, our findings may have implications for the treatment of anxiety disorders.
\end{abstract}

Neuropsychopharmacology (20 I2) 37, 1204-1215; doi:10.1038/npp.20 I I.307; published online I4 December 20 I I

Keywords: fear memory; reconsolidation; extinction; generalization; noradrenergic modulation; anxiety disorders

\section{INTRODUCTION}

The process of reconsolidation, the protein-synthesisdependent restabilization of a memory upon retrieval, enables the modification of memory representation (Nader et al, 2000). We previously demonstrated that disrupting reconsolidation by administering the $\beta$-adrenergic receptor antagonist propranolol $\mathrm{HCl}$ before reactivation selectively 'deleted' the emotional expression of a fear memory in humans (ie, startle fear responding) (Kindt et al, 2009; Soeter and Kindt, 2010, 2011a). Importantly, the fearerasing effects following the pharmacological manipulation were not restricted to the feared cue itself, but instead generalized to category-related information (Soeter and

*Correspondence: Professor M Kindt, Department of Clinical Psychology, Faculty of Social and Behavioural Sciences, University of Amsterdam, Weesperplein 4, 1018 XA Amsterdam, The Netherlands, Tel: + 3120525 68I0, Fax: + 3120639 1369,

E-mail: m.kindt@uva.nl

Received I4 June 201।; revised | November 201 I; accepted 3 November 2011
Kindt, 2011a). Given that fear generalization lies at the heart of many anxiety disorders (Lissek et al, 2008), targeting the process of reconsolidation may provide a novel therapeutic strategy in the treatment of (for instance) post-traumatic stress disorder. However, there are a number of conditions that may prevent reconsolidation from occurring, such as the strength of memories (Suzuki et al, 2004; Wang et al, 2009). If we are to target reconsolidation in patients suffering from post-traumatic stress disorder, strong fear memory should evidently not act as a constraint on reconsolidation.

To date, a substantial body of evidence supports the noradrenergic modulation in the formation of emotional memory (McGaugh and Roozendaal, 2009). Recently, we demonstrated that stimulation of the noradrenergic system during memory formation strengthened the emotional expression of human associative fear memory (Soeter and Kindt, 2011b). That is, the excessive release of noradrenaline during memory formation not only delayed the 'process of extinction' $48 \mathrm{~h}$ later, but also generated a superior recovery of fear following re-exposure to the original 
stressor. These findings thus suggest that noradrenaline may play an important role in the etiology and maintenance of anxiety disorders. However, the effect of noradrenaline on fear generalization (ie, a main characteristic of anxiety disorders) currently remains unknown. The generalization of fear seems to be dependent on the strength of the memory as operationalized by training intensity (Laxmi et al, 2003). Hence, an interesting question is whether the noradrenaline-induced strengthening of associative fear memory also promotes the generalization of fear responding. At the same time, the stimulation of the noradrenergic system during memory formation should not impair the disruption of reconsolidation if we are to target reconsolidation clinically.

Here, we addressed these issues by using a differential fear conditioning procedure allowing selective reactivation of one of two categorically distinct fear associations sharing the same aversive outcome and a test of fear generalization. Testing included different phases across three consecutive days, each separated by $24 \mathrm{~h}$ (see Figure 1a). During acquisition (day 1), two fear-relevant stimuli $\left(\mathrm{CS}_{\text {Spider }}-\mathrm{CS} 2_{\text {Gun }}\right)$ were repeatedly paired with an aversive electric stimulus (US), whereas a fear-irrelevant stimulus was not ( $\mathrm{CS} 3_{\text {Mug }}$ ) (Supplementary Figure S1). Furthermore - in Experiment I-the formation of fear memory was manipulated by the systemic administration of yohimbine $\mathrm{HCl}$ (day 1), an $\alpha_{2}$-adrenergic receptor antagonist supposed to stimulate central noradrenergic activity by blocking the $\alpha_{2}$-adrenergic autoreceptor (Charney et al, 1987; Peskind et al, 1995; Soeter and Kindt, $2011 b)$. To reach peak plasma levels upon completion of the acquisition phase, participants $(n=30)$ received, in a double-blind manner, an oral dose of either $20 \mathrm{mg}$ of yohimbine $\mathrm{HCl}$ or placebo pill $30 \mathrm{~min}$ before fear learning (day 1) (time for peak value yohimbine $\mathrm{HCl}<1 \mathrm{~h}$; Grasing et al, 1996). On day 2 , the reconsolidation of one of the fear associations (CS1) was manipulated by the systemic administration of propranolol $\mathrm{HCl}-\mathrm{a} \beta$-adrenergic receptor antagonist that indirectly targets the protein synthesis required for reconsolidation by inhibiting the noradrenaline-stimulated cAMP response element binding (CREB) phosphorylation (Thonberg et al, 2002). In view of the peak plasma concentrations of propranolol $\mathrm{HCl}$ (Gilman and Goodman, 1996), all of the participants received, in a single-blind manner, an oral dose of $40 \mathrm{mg}$ of propranolol $\mathrm{HCl} 90$ min before the selective reactivation of the CS1 memory (day 2). (In line with animal studies (eg, Debiec and LeDoux, 2004), we previously demonstrated that (1) a reactivation trial in combination with placebo pill and (2) the omission of memory reactivation after propranolol $\mathrm{HCl}$ intake yielded intact fear responding (Kindt et al, 2009; Soeter and Kindt, 2010). Taken together, these findings indicate that both the oral administration of propranolol $\mathrm{HCl}$ and the reactivation of the fear memory are necessary for the observed fear-erasing effects.). Administering pills before reactivation does not-however-rule out a possible effect of the pharmacological manipulation on the retrieval of the fear memory itself. Therefore, the participants in Experiment II $(n=10)$ received, in a single-blind manner, an oral dose of propranolol $\mathrm{HCl}$ subsequent to memory reactivation. Memory retention was tested $24 \mathrm{~h}$ later (ie, first test trial day 3), followed by an extinction procedure, reminder shock, and a test of fear generalization. Expression of fear was measured using startle fear potentiation (Hamm and Weike, 2005). We obtained skin conductance responding and retrospective US expectancy ratings to assess the anticipation of threat (Weike et al, 2007). Here, the US expectancy was measured retrospectively instead of 'online' (Soeter and Kindt, 2010, $2011 \mathrm{a}, \mathrm{b})$ to prevent the expectancy ratings from interfering with the measurement of electrodermal activity. Salivary $\alpha$ amylase and blood pressure levels were determined to ensure that the drug manipulations exerted its intended physiological effect (Stegeren et al, 2006, 2009). See Supplementary Materials and methods for a detailed description of the apparatus and materials. We hypothesized that the yohimbine $\mathrm{HCl}$ manipulation during acquisition would strengthen the fear memory and thereby (1) act as a constraint on the reconsolidation of the CS1 fear association, (2) delay the process of extinction learning, and (3) promote the generalization of fear responding, relative to placebo pill.

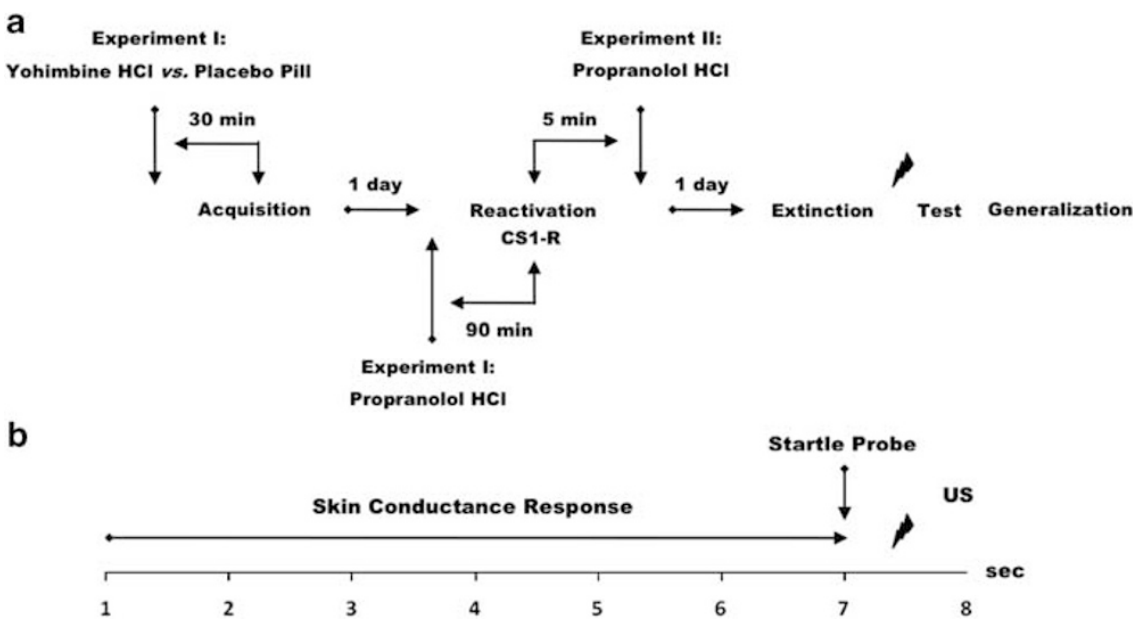

Figure I Schematic of the experimental design (a) and the $\mathrm{CSI}^{+}$or $\mathrm{CS}^{+}$conditioning trial (b). In the $\mathrm{CSI}^{-}, \mathrm{CS}^{-}, \mathrm{CS}^{-}$, and $\mathrm{CSI}_{-} \mathrm{R}_{\text {trials, }}$ no $\mathrm{US} \mathrm{waS}$ delivered. CS, conditioned stimuli. 


\section{MATERIALS AND METHODS}

\section{Participants}

In all, 40 undergraduate students (10 men, 30 women) from the University of Amsterdam ranging in the age of 18-26 years (mean $\pm S D$ age, $20.7 \pm 1.9$ years) participated in the study. Participants were assessed to be free from any current or previous medical or psychiatric condition that would contraindicate taking a single dose of yohimbine $\mathrm{HCl}$ (20 mg) and propranolol $\mathrm{HCl}$ (40 mg) (ie, pregnancy; seizure disorder; respiratory disorder; cardiovascular disease; blood pressure $\leq 90 / 60$ or $\geq 140 / 90 \mathrm{mmHg}$; diabetes; liver/kidney disorder; depression; or psychosis). To eliminate individuals who might have difficulty with any temporary symptoms induced by either drug manipulation, an additional exclusion criterion contained a score $\geq 26$ on the Anxiety Sensitivity Index (ASI) (Peterson and Reiss, 1992). All participants who were enrolled completed the study. The participants in Experiment I were randomly assigned to one of two conditions, with the restriction that conditions were matched on Trait Anxiety (STAI-T) (Spielberger et al, 1970), Spider Phobic Questionnaire (SPQ) (Klorman et al, 1974), and ASI scores as close as possible (see Table 1). Participants received either partial course credits or were paid a small amount $(€ 42,-)$ for their participation in one of the experiments. The ethical committee of the University of Amsterdam approved the study and informed consent was obtained from all participants.

\section{Experimental Procedure}

Participants were subjected to a differential fear conditioning procedure, with three pictures serving as conditioned stimuli $\left(\mathrm{CS}_{\text {Spider }}-\mathrm{CS} 2_{\mathrm{Gun}}-\mathrm{CS} 3_{\mathrm{Mug}}\right)$. The two fear-relevant pictures (CS1, CS2) were paired with an electric stimulus, whereas the fear-irrelevant picture (CS3) was not. We employed fear-relevant stimuli because they lead to a superior conditioning of aversive associations and are especially resistant to extinction learning compared with fear-irrelevant cues (Mineka and Öhman, 2002; Lang et al, 2005). Moreover, given that most anxiety disorders are associated with these categories of stimuli (Mineka and Öhman, 2002), we are specifically interested in targeting stronger fear memory. One of the fear-relevant stimuli (CS2) served as control for the other fear-relevant stimulus (CS1). However, since fear-relevant stimuli are known to

Table I Mean Values (SD) of the Reported Spider Fear, Trait Anxiety, Anxiety Sensitivity, Shock Intensity, and US Evaluation for the Yohimbine $\mathrm{HCl}$ and Placebo Pill Condition and the Propranolol after Reactivation Group

\begin{tabular}{lcccc}
\hline & $\begin{array}{c}\text { Yohimbine HCl } \\
\text { propranolol }\end{array}$ & $\begin{array}{c}\text { Placebo pill } \\
\text { propranolol }\end{array}$ & $\begin{array}{c}\text { Propranolol after } \\
\text { reactivation }\end{array}$ & T-test \\
\hline Spider fear & $4.6(3.3)$ & $6.3(5.3)$ & $4.2(4.5)$ & $\mathrm{ts}_{28}<1.04$ \\
Trait anxiety & $37.5(8.0)$ & $36.3(7.9)$ & $32.0(10.1)$ & $\mathrm{ts}_{28}<1.53$ \\
Anxiety sensitivity & $9.2(5.4)$ & $8.5(5.0)$ & $7.8(5.6)$ & $\mathrm{ts}_{28}<1$ \\
Shock intensity & $16.4(6.9)$ & $14.5(4.7)$ & $17.3(5.6)$ & $\mathrm{ts}_{28}<1.35$ \\
US evaluation & $-2.7(1.0)$ & $-2.8(0.6)$ & $-2.4(0.9)$ & $\mathrm{ts}_{28}<1$ \\
\hline
\end{tabular}

have an innate prepotency to elicit fear responses (Lovibond et al, 1994), we employed an additional fear-irrelevant control stimulus (CS3) to verify whether the procedure was capable of neutralizing the acquired fear responding. Testing included several phases across three subsequent days, each separated by $24 \mathrm{~h}$. During each session, participants sat behind a table with a computer monitor at a distance of $50 \mathrm{~cm}$ in a sound-attenuated room. Each session began with a 1-min acclimation period consisting of $70 \mathrm{~dB}$ broadband noise, which continued throughout the session as background noise, followed by a habituation phase consisting of 10 startle probes to reduce initial startle reactivity. Characteristics of the CSs, trial order, ITIs, and startle probes during memory reactivation (day 2) and extinction, testing (day 3) were similar to acquisition (day 1). Assignment of the pictures as $\mathrm{CS}^{+}$and $\mathrm{CS}^{+}$ was counterbalanced across participants.

Acquisition-day 1. Before participants subscribed to the study, they were already informed about the pill administrations and the electric stimulus. Upon arrival at the first testing day, details of the various study procedures (eg, EMG electrodes, electric stimulus, side effects of the pharmacological treatments, medical screening) were explained and possible questions were answered. Participants who agreed to enroll in the study were interviewed with regard to their health and any medical or psychiatric conditions that would contraindicate taking a single dose of yohimbine $\mathrm{HCl}(20 \mathrm{mg})$ and propranolol $\mathrm{HCl}(40 \mathrm{mg})$. In addition, blood pressure was measured. Once a participant was medically cleared, written informed consent was obtained and the ASI, SPQ, and STAI were administered. Furthermore, saliva samples were collected. To this end, participants were instructed just to place the swab in their mouths for $3 \mathrm{~min}$.

After attachment of the startle, skin conductance, and shock electrodes, the intensity of the US was determined. Starting at an intensity of $1 \mathrm{~mA}$, the level of a 2 -ms aversive electric stimulus delivered to the wrist of the non-preferred hand was gradually increased. The intensity of shock was individually set at a level defined by the participant as 'uncomfortable, but not painful' and remained set to this intensity throughout the following days. To test for the potential effects of yohimbine $\mathrm{HCl}$ on the fear-potentiated startle reflex (Davis et al, 1993), 10 baseline startle probes (noise alone; NA) were presented before pill intake. Afterwards, participants were detached from the experimental setup and received, in a double-blind manner, an oral dose of either $20 \mathrm{mg}$ of yohimbine $\mathrm{HCl}$ or placebo pill. To reach peak plasma levels upon completion of the acquisition phase (Grasing et al, 1996), a resting period of $30 \mathrm{~min}$ was inserted. Participants were offered magazines to read. Before acquisition, participants were attached to the experimental apparatus and were informed with regard to the CSs. They were instructed that two of the pictures would be followed by an electric stimulus in most of the cases, whereas the third picture would never be followed by the US. They were told to learn to predict whether an electric stimulus would occur or not on the basis of the three pictures.

In the acquisition phase, the $\mathrm{CS}^{+}{ }^{+} \mathrm{CS}^{+}$, and $\mathrm{CS}_{3}^{-}$were presented five times for $8 \mathrm{~s}$. The startle probe was presented

Neuropsychopharmacology 
$7 \mathrm{~s}$ after CS onset and was followed by the US $500 \mathrm{~ms}$ later $\left(\mathrm{CS}^{+}{ }^{+}\right.$and $\mathrm{CS} 2^{+}$) (see Figure $1 \mathrm{~b}$ ). To reduce the possibility that the reactivation trial on day 2 resulted in extinction learning, the first presentation of both the $\mathrm{CS}^{+}{ }^{+}$and $\mathrm{CS}_{2}{ }^{+}$ was unreinforced (LaBar et al, 1998). Five baseline startle probes were presented alone (NA). Order of trial type was randomized within blocks (ie, $\mathrm{CS}^{+}, \mathrm{CS}^{+}, \mathrm{CS}^{-}$, and $\mathrm{NA}$ ). Intertrial intervals (ITI) varied between 15, 20, and $25 \mathrm{~s}$, with a mean of $20 \mathrm{~s}$.

The STAI-S was filled out both before and upon completion of the acquisition phase. In addition, blood pressure as well as saliva samples were collected. At the conclusion of the experiment, participants were asked to evaluate the pleasantness of the US. Furthermore, they were explicitly instructed to remember what they had learned during acquisition. These instructions were included to enhance retention of the CS-US contingency on the following days (Norrholm et al, 2006) and to prevent participants from erroneously expecting a different contingency scheme during subsequent testing. The procedure in Experiment II, Propranolol after Reactivation, was similar to Experiment I, except for pill administration and resting period.

Memory reactivation - day 2. To substantiate consolidation of the fear memory, a break of $24 \mathrm{~h}$ after acquisition was inserted. All of the participants received, in a single-blind manner, an oral dose of $40 \mathrm{mg}$ of propranolol $\mathrm{HCl} 90 \mathrm{~min}$ before memory reactivation (CS1-R) - even though they were informed that they could also receive a placebo pill. The STAI-S was filled out both before pill administration and upon completion of the experiment. In addition, at these time points, blood pressure and saliva samples were collected.

After electrode attachment, participants were told that the same three pictures would be presented and they were asked to remember what they had learned during acquisition. They were again instructed that two of the pictures would be followed by an electric stimulus in most of the cases, whereas the third picture would never be followed by the US. In the memory reactivation phase, a single unreinforced CS1-R was presented for $8 \mathrm{~s}$, followed by a startle probe presented alone. The procedure in Experiment II, Propranolol after Reactivation, was similar to Experiment I, except for pill administration, which occurred $5 \mathrm{~min}$ after reactivation of the memory.

Extinction, testing - day 3. Upon arriving at the experimental site, blood pressure and saliva samples were again collected. In addition, the STAI-S was completed. After attachment of the electrodes, the participants were informed that the same three pictures provided during acquisition would be presented. No further instructions were given. In the extinction phase, participants were exposed to the three pictures $\left(\mathrm{CS}^{-}, \mathrm{CS}^{-}\right.$, and $\left.\mathrm{CS}^{-}\right)$for 10 times without the electric stimulus (US). Startle probes were again presented $7 \mathrm{~s}$ after CS onset. Furthermore, 10 startle probes were presented alone (NA). After the extinction procedure, we presented an unsignaled reminder shock to reinstate the expression of the original fear memory. Evidence for a reinstatement effect is indicated by an increase of the differential conditioned response from the last extinction trial to the first trial at test. We predicted that the unsignaled reminder shock would not result in a return of fear to the reactivated stimulus (CS1) given that propranolol $\mathrm{HCl}$ is supposed to disrupt the reconsolidation of the reactivated fear memory (CS1-US). We further predicted that yohimbine $\mathrm{HCl}$ would enhance the return of fear (CS2) following the unsignaled reminder shock (US) (see also, Soeter and Kindt, 2011b). Therefore, we presented only one as opposed to the traditional procedure of three unsignaled USs to avoid a ceiling effect in the return of fear for the participants who received a placebo pill during fear acquisition (day 1) (Norrholm et al, 2006; Kindt et al, 2009; Soeter and Kindt, 2010). The time between the last extinction trial and the reinstating US was 19 s. Following the unsignaled US, participants were again presented with 1 $\mathrm{CS}^{-}, \mathrm{CS}_{2}^{-}, \mathrm{CS}^{-}$, and NA trial (ie, reinstatement testing). The time between the reinstating USs and reinstatement testing was $18 \mathrm{~s}$. Next, generalization testing took place. That is, participants were exposed to category-related pictures $\left(\mathrm{G}_{\mathrm{p}} \mathrm{CS} 1, \mathrm{G}_{\mathrm{p}} \mathrm{CS} 2\right.$, and $\mathrm{G}_{\mathrm{p}} \mathrm{CS} 3$ ) and category-related words $\left(\mathrm{G}_{\mathrm{w}} \mathrm{CS} 1, \mathrm{G}_{\mathrm{w}} \mathrm{CS} 2\right.$, and $\mathrm{G}_{\mathrm{w}} \mathrm{CS} 3$ ) (see Supplementary Figure $\mathrm{S} 1$ ). The order of generalization stimuli (ie, pictures $v s$ words) was counterbalanced across participants. At the conclusion of the experiment, participants completed the STAI-S and judged the pleasantness of the US. In addition, participants were asked to indicate for each phase (beginning $v s$ end) of the experiment to what extent they had expected the US after each of the CSs. The procedure in Experiment II, Propranolol after Reactivation, was similar to Experiment I.

\section{Statistical Analysis}

State anxiety, salivary $\alpha$-amylase, and systolic as well as diastolic blood pressure were subjected to a 2 (condition: yohimbine $\mathrm{HCl} v s$ placebo pill) $\times 2$ (moment: before $v s$ after pill intake) mixed analysis of variance (ANOVA). Startle responses, electrodermal activity, and US expectancy ratings were analyzed by means of a mixed ANOVA for repeated measures with condition (ie, yohimbine $\mathrm{HCl} v s$ placebo pill) as between-subjects factor and stimulus (ie, simple contrasts: CS1 vs CS3 and CS2 vs CS3) and trial (ie, stimulus presentation) as within-subjects factors. The differential response (CS1 vs CS3 and CS2 vs CS3) was compared over testing phases, respectively (first trial $v s$ last trial). To determine the speed of extinction learning, a 2 (condition: yohimbine $\mathrm{HCl} v s$ placebo pill) $\times 2$ (stimulus: CS1 vs CS3 and CS2 vs CS3) $\times 5$ (trials: averaging over each two consecutive extinction trials) mixed ANOVA was performed. To test whether the two conditioned stimuli (ie, spider and gun) were equally affected by the drug manipulation, we performed a 2 (trial: stimulus presentation) $\times 2$ (stimulus: CS1 vs CS3) $\times 2$ (stimulus category: spider $v s$ gun) mixed ANOVA. Planned comparisons between the CS1 and CS2 stimuli were performed separately. Missing data due to artifacts (ie, $1.13 \%$ of the trials) were not replaced and hence excluded from the analyses. Significance was set at $p<0.05$.

\section{RESULTS}

\section{Manipulation Check Drug Administration}

Analysis of the effect of the yohimbine $\mathrm{HCl}$ manipulation on blood pressure and sAA level during fear acquisition (day 1) 
revealed the expected increase in both systolic and diastolic blood pressure (moment $\times$ condition, $\mathrm{F}_{1,28}=26.58$, $p<0.001, \eta_{\mathrm{p}}^{2}=0.49 ; \mathrm{F}_{1,28}=12.24, p<0.01, \eta_{\mathrm{p}}^{2}=0.30$, respectively), as well as salivary $\alpha$-amylase (Stegeren et al, 2009) (moment $\times$ condition, $\mathrm{F}_{1,23}=6.50, p<0.05, \eta_{\mathrm{p}}^{2}=0.22$ ) in comparison to placebo pill. However, the yohimbine $\mathrm{HCl}$ manipulation during fear acquisition did not affect the reported state anxiety that was assessed before and upon completion of the acquisition phase (moment $\times$ condition, $\mathrm{F}_{1,28}<1.45$ ) (see also, Table 2).

The propranolol $\mathrm{HCl}$ manipulation during memory reactivation (day 2) did not differentially affect the $\mathrm{BP}$ and sAA between conditions (moment $\times$ condition, $\mathrm{F}_{1,28}<1.92$ ). In both the yohimbine and placebo pill group, we observed a significant decrease in systolic and diastolic BP (moment, $\mathrm{F}_{1,28}=92.22, p<0.001, \eta_{\mathrm{p}}^{2}=0.77 ; \mathrm{F}_{1,28}=39.81$, $p<0.001, \eta_{\mathrm{p}}^{2}=0.59$, respectively), as well as in the amylase level (Stegeren et al, 2006) (moment, $\mathrm{F}_{1,22}=7.95, p=0.01$, $\eta_{\mathrm{p}}^{2}=0.27$ ) following propranolol $\mathrm{HCl}$ administration, indicating that the pill manipulation exerted its intended physiological effect. Consistent with other studies (Grillon et al, 2004), the propranolol $\mathrm{HCl}$ manipulation during memory retrieval did not affect the reported state anxiety that was assessed before and upon completion of the reactivation phase (moment, $\mathrm{F}_{1,28}<1$; moment $\times$ condition, $\left.\mathrm{F}_{1,28}<1\right)$. The decrease in $\mathrm{BP}, \mathrm{sAA}$, and reported state anxiety during memory reactivation (day 2) in Experiment II, Propranolol after Reactivation, did not differ from both the yohimbine $\mathrm{HCl}$ and placebo pill condition (moment $\times$ condition, $\mathrm{F}_{1,28}<1.98$ ) (see also, Table 3 ).

\section{Experiment I, Yohimbine $\mathrm{HCl}$ vs Placebo Pill}

Startle fear responding. Acquisition-day 1 ANOVA showed fear conditioning on day 1 by a significant increase of the differential startle response (ie, simple contrasts: $\mathrm{CS} 1_{\text {Spider }}$ vs $\mathrm{CS} 3_{\mathrm{Mug}}-\mathrm{CS} 2_{\text {Gun }}$ vs $\mathrm{CS} 3_{\mathrm{Mug}}$ ) from trials 1 to 5 (stimulus $\times$ trial, $\quad \mathrm{F}_{1,28}=21.73, \quad p<0.001, \quad \eta_{\mathrm{p}}^{2}=0.44$; $\mathrm{F}_{1,28}=19.85, p<0.001, \eta_{\mathrm{p}}^{2}=0.42$, respectively). We observed no difference in responses to the first trial of acquisition $\left(\begin{array}{lllll}\mathrm{CS}_{1} \text { spider } & v s & \mathrm{CS} 2_{\text {Gun }} & v s & \mathrm{CS}_{\text {Mug }}\end{array}\right)$ (stimulus, $\left.\mathrm{F}_{2,27}<1\right)$, indicating that the fear relevancy of the pictures did not affect startle fear responding in the absence of associative

Table 2 Mean Values (SD) of the Systolic and Diastolic Blood Pressure (in $\mathrm{mmHg}$ ) and Amylase Level (in $\mathrm{U} / \mathrm{ml}$ ) Pre- and Post-Pill Intake during Fear Acquisition for the Yohimbine $\mathrm{HCl}$ and Placebo Pill Condition (ie, Experiment I)

\begin{tabular}{lccc}
$\begin{array}{l}\text { Fear acquisition } \\
\text { yohimbine HCI }\end{array}$ & Pre-pill intake & Post-pill intake & $\begin{array}{c}\text { T-test: } \\
\text { two-tailed }\end{array}$ \\
\hline $\begin{array}{l}\text { Yohimbine condition } \\
\text { Systolic BP }\end{array}$ & $126.1(\mathrm{SD}=10.1)$ & $138.0(\mathrm{SD}=11.9)$ & $t_{14}=-4.84, p<0.00$ । \\
Diastolic BP & $72.5(\mathrm{SD}=6.3)$ & $77.7(\mathrm{SD}=8.3)$ & $t_{14}=-2.72, p<0.05$ \\
SAA Level & $91.4(\mathrm{SD}=127.1)$ & $168.9(\mathrm{SD}=233.9)$ & $t_{11}=-2.36, p<0.05$ \\
& & & \\
Placebo pill condition & & & \\
Systolic BP & $125.3(\mathrm{SD}=14.7)$ & $120.8(\mathrm{SD}=8.9)$ & $t_{14}=2.22, p<0.05$ \\
Diastolic BP & $73.0(\mathrm{SD}=7.5)$ & $70.3(\mathrm{SD}=7.0)$ & $t_{14}=2.25, p<0.05$ \\
SAA Level & $103.1(\mathrm{SD}=105.2)$ & $75.7(\mathrm{SD}=62.9)$ & $t_{12}<1$ \\
\hline
\end{tabular}

Table 3 Mean Values (SD) of the Systolic and Diastolic Blood Pressure (in $\mathrm{mmHg}$ ) and Amylase Level (in $\mathrm{U} / \mathrm{ml}$ ) Pre- and Post Propranolol $\mathrm{HCl}$ Administration during Memory Reactivation for the Yohimbine $\mathrm{HCl}$ and Placebo Pill Condition (ie, Experiment I) and the Propranolol after Reactivation Group (ie, Experiment II)

\begin{tabular}{|c|c|c|c|}
\hline $\begin{array}{l}\text { Memory reactivation } \\
\text { propranolol } \mathrm{HCl}\end{array}$ & Pre-pill intake & Post-pill intake & $\begin{array}{l}\text { T-test: } \\
\text { two-tailed }\end{array}$ \\
\hline \multicolumn{4}{|l|}{ Yohimbine condition } \\
\hline Systolic BP & $130.3(\mathrm{SD}=\mid 1.2)$ & $113.3(\mathrm{SD}=11.7)$ & $t_{14}=6.52, p<0.001$ \\
\hline Diastolic BP & $75.0(\mathrm{SD}=7.6)$ & $67.8(\mathrm{SD}=6.7)$ & $t_{14}=4.56, p<0.001$ \\
\hline sAA Level & $193.0(\mathrm{SD}=261.4)$ & $32.1(\mathrm{SD}=38.4)$ & $t_{11}=2.21, p<0.05$ \\
\hline \multicolumn{4}{|l|}{ Placebo pill condition } \\
\hline Systolic BP & $125.5(\mathrm{SD}=9.2)$ & $110.3(\mathrm{SD}=7.8)$ & $t_{14}=7.53, p<0.001$ \\
\hline Diastolic BP & $70.1(\mathrm{SD}=5.6)$ & $65.8(\mathrm{SD}=5.5)$ & $t_{14}=4.72, p<0.05$ \\
\hline sAA Level & $96.1(\mathrm{SD}=105.6)$ & $41.2(\mathrm{SD}=38.0)$ & $t_{11}=2.32, p<0.05$ \\
\hline \multicolumn{4}{|l|}{ Propranolol after reactivation } \\
\hline Systolic BP & $121.3(\mathrm{SD}=4.9)$ & $107.1(\mathrm{SD}=7.0)$ & $t_{9}=5.94, p<0.001$ \\
\hline Diastolic BP & $73.2(\mathrm{SD}=8.7)$ & $67.8(\mathrm{SD}=8.1)$ & $t_{9}=3.28, p<0.05$ \\
\hline sAA Level & $56.9(\mathrm{SD}=41.8)$ & $30.1(S D=36.2)$ & $t_{9}=2.55, p<0.05$ \\
\hline
\end{tabular}

learning (see also, Soeter and Kindt, 2011a). Moreover, fear responses to the reinforced pictures $\left(\mathrm{CS}_{\mathrm{Spider}} v s \mathrm{CS} 2_{\mathrm{Gun}}\right)$ were equally acquired (stimulus $\times$ trial, $\mathrm{F}_{1,28}<1$; Figure $2 \mathrm{a}$ and $b$ ). Furthermore, the administration of yohimbine $\mathrm{HCl}$ did not directly affect the fear learning given that we observed no difference during acquisition between the two conditions (stimulus $\times$ trial $\times$ condition, $F_{1,28}<2.09$ ). Yohimbine $\mathrm{HCl}$ did also not affect the startle response per se as we found no effect on the habituation trials that were presented before and after pill administration (moment $x$ trial $\times$ condition, $\mathrm{F}_{9,20}<1.06$ ).

Memory reactivation - day 2 The two groups (yohimbine $\mathrm{HCl} v s$ placebo pill) expressed similar levels of differential startle potentiation (CS1-R vs NA) during memory reactivation (day 2) (stimulus $\times$ condition, $\left.\mathrm{F}_{1,28}<1\right)$. Since the NA trial always followed the reactivation trial (CS1-R) on day 2, we further compared the CS1-R with the last trial of habituation (ie, an NA trial). This analysis also revealed a similar level of startle potentiation during memory reactivation for both conditions (stimulus $\times$ condition, $\left.\mathrm{F}_{1,28}<1.46\right)$. Furthermore, the absence of a significant change in startle fear responding (CS1 vs NA) from the last trial of acquisition to memory reactivation (stimulus $\times$ trial $\times$ condition, $\mathrm{F}_{1,28}<1$ ) demonstrates that the acquired fear memory was equally well consolidated in the two groups.

Memory retention-day 3 In both the yohimbine and placebo pill group, the administration of propranolol $\mathrm{HCl}$ significantly decreased startle potentiation to the reactivated CS1 from the last trial of acquisition to the first extinction trial $48 \mathrm{~h}$ later (CS1 vs CS3; stimulus $\times$ trial, $\left.\mathrm{F}_{1,28}=15.98, \quad p<0.001, \quad \eta_{\mathrm{p}}^{2}=0.36\right)$, irrespective of the reactivated stimulus (ie, spider $v s$ gun) (stimulus $\times$ trial $\times$ category, $\left.F_{1,26}<1.16\right)$. We even no longer observed differential startle responding to the reactivated CS1 on the first trial of extinction learning (CS1 vs CS3; $t_{14}<1.25$; Figure $2 \mathrm{a}$ and $\mathrm{b}$ ), indicating that the yohimbine $\mathrm{HCl}$ 
a
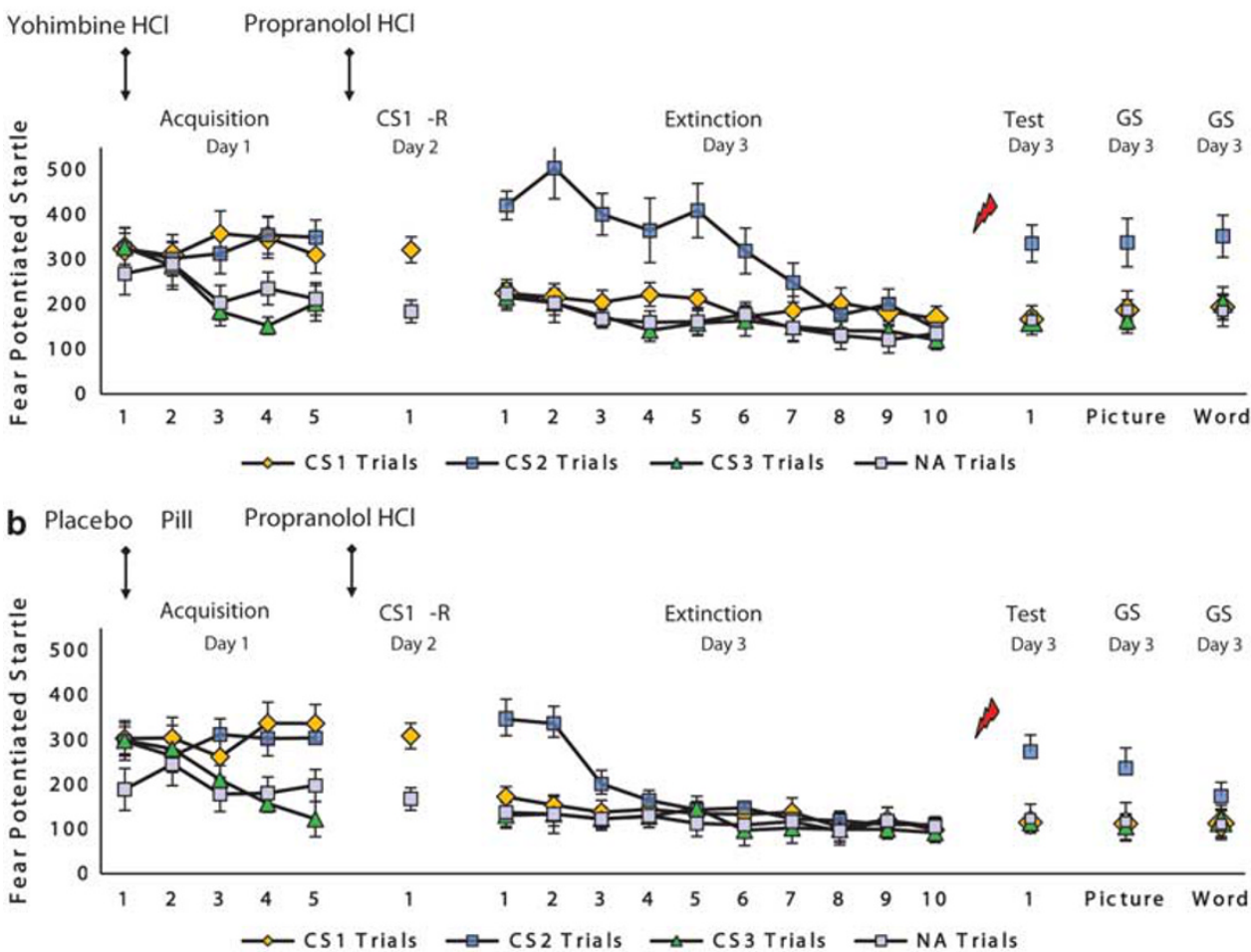

C

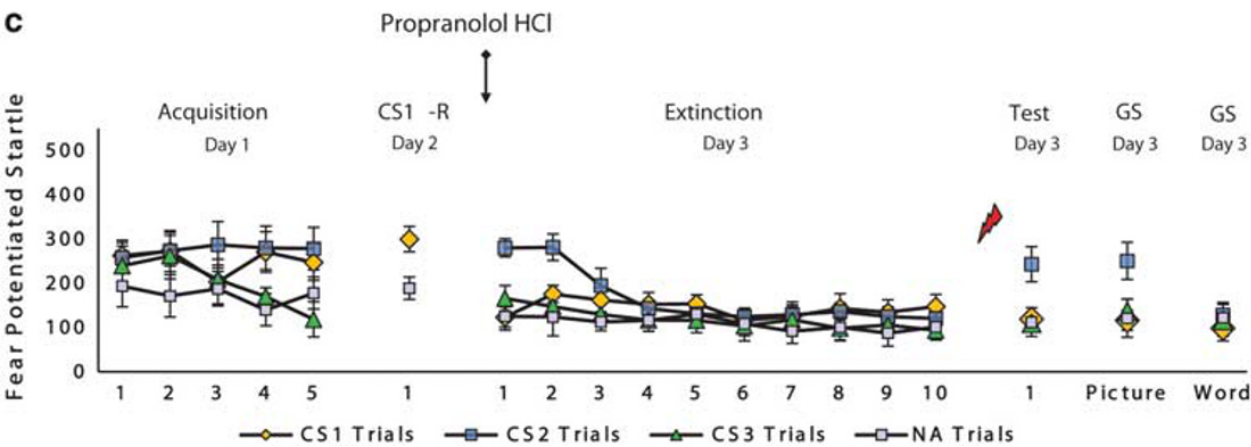

Figure 2 Mean startle potentiation to the fear-conditioned stimuli (CSI and CS2), the control stimulus (CS3), and noise alone (NA) trials during acquisition, memory reactivation, extinction, test, and generalization for the (a) yohimbine $\mathrm{HCl}$-propranolol $\mathrm{HCl}$ and (b) placebo pill-propranolol $\mathrm{HCl}$ condition (ie, Experiment I), and the (c) propranolol HCl after reactivation group (ie, Experiment II). Error bars represent SEM.

manipulation did not prevent the disruption of reconsolidation $24 \mathrm{~h}$ later. Conversely, startle responses to the nonreactivated CS2 remained stable from acquisition to extinction learning $48 \mathrm{~h}$ later in the yohimbine as well as placebo pill condition (CS2 vs CS3; stimulus $\times$ trial, $\mathrm{F}_{1,28}<1.12$ ).

Extinction learning - day 3 Given that responses to the reactivated CS1 were already eliminated on the first trial of fear extinction (day 3), we observed no extinction learning to the CS1 stimulus (CS1 vs CS3) in both the yohimbine and placebo pill group (trial $1 v s$ trial 10 ; stimulus $\times$ trial, $\mathrm{F}_{1,28}<1$ ). In contrast, startle responses to the non-reactivated CS2 decreased similarly from the first extinction trial to the last trial of extinction learning in the yohimbine and placebo pill condition (CS2 vs CS3; stimulus $\times$ trial, $\mathrm{F}_{1,28}=53.52, p<0.001$, $\eta_{\mathrm{p}}^{2}=0.66$; stimulus $\times$ trial $\times$ condition, $\mathrm{F}_{1,28}<1$ ). However, we observed a significant difference in the speed of the extinction learning process between the two groups (CS2 vs CS3 and CS1 vs CS2; stimulus $\times$ trial $\times$ condition, $\mathrm{F}_{1,28}=21.49, p<0.001$, $\eta_{\mathrm{p}}^{2}=0.43 ; \quad \mathrm{F}_{1,28}=23,41, \quad p<0.001, \quad \eta_{\mathrm{p}}^{2}=0.46, \quad$ respectively), irrespective of the non-reactivated stimulus (ie, spider $v s$ gun) (stimulus $\times$ trial $\times$ condition $\times$ category, $\mathrm{F}_{1,26}<1$ ). Bonferroni-adjusted pairwise comparisons indeed showed that the differential startle response to the non-reactivated stimulus (CS2 vs CS3) only reached significance on the first trials of extinction learning (trials 1 and 2) in the placebo pill condition $(p<0.001$; Figure $2 \mathrm{~b})$. Conversely, the differential startle response to the non-reactivated stimulus (CS2 vs CS3) remained significant up to trials 5 and 6 of extinction learning in the yohimbine group (all $p$ 's $<0.001$; Figure $2 \mathrm{a}$ ), indicating that the $\alpha_{2}$-adrenergic drug strongly delayed the extinction learning process (see also, Soeter and Kindt, 2011b).

Reinstatement testing - day 3 Contrary to our expectations, the administration of yohimbine $\mathrm{HCl}$ relative to placebo pill did not result in a superior recovery of fear to the non-reactivated CS2 following the reminder shock (CS2 vs CS3; stimulus $\times$ trial $\times$ condition, $\mathrm{F}_{1,28}<1$ ). However, in both the yohimbine and placebo pill condition, the 
differential startle response to the non-reactivated CS2 significantly increased from the last trial of extinction to the first trial at test (stimulus $\times$ trial, $F_{1,28}=26.56, p<0.001$, $\eta_{\mathrm{p}}^{2}=0.49$; Figure $2 \mathrm{a}$ and $\mathrm{b}$ ). Most importantly, the reminder shock following extinction learning did not unveil a recovery of fear to the reactivated CS1 in the yohimbine as well as placebo pill condition (CS1 vs CS3; stimulus $\times$ trial, $\mathrm{F}_{1,28}<1.24$; CS1 vs CS3; stimulus $\times$ trial, $\mathrm{F}_{1,28}=36.88$, $\left.p<0.001, \eta_{\mathrm{p}}^{2}=0.57\right)$. This finding indicates that propranolol $\mathrm{HCl}$ effectively disrupted the reconsolidation of the reactivated fear memory and that the administration of yohimbine $\mathrm{HCl}$ before fear learning did not prevent this process $24 \mathrm{~h}$ later.

Generalization testing - day 3 We observed a significant generalization of fear to the category-related picture of the non-reactivated CS2 in both the yohimbine and placebo pill group $\left(\mathrm{G}_{\mathrm{p}} \mathrm{CS} 2\right.$ vs $\mathrm{G}_{\mathrm{p}} \mathrm{CS} 3$ and $\mathrm{G}_{\mathrm{p}} \mathrm{CS} 1$ vs $\mathrm{G}_{\mathrm{p}} \mathrm{CS} 2$; main effect of stimulus, $\mathrm{F}_{1,28}=31.29, p<0.001, \eta_{\mathrm{p}}^{2}=0.53$; main effect of stimulus, $\mathrm{F}_{1,28}=25.55, \quad p<0.001, \eta_{\mathrm{p}}^{2}=0.48$, respectively). Conversely, the category-related picture of the reactivated CS1 did not reveal any fear response in the yohimbine and placebo pill condition $\left(\mathrm{G}_{p} \mathrm{CS} 1\right.$ vs $\mathrm{G}_{p} \mathrm{CS} 3$; main effect of stimulus, $\mathrm{F}_{1,28}<1.16$; Figure $2 \mathrm{a}$ and $\mathrm{b}$ ). Notably, a significant difference in fear generalization for the word cue of the nonreactivated $\mathrm{CS} 2$ was observed between the two groups $\left(\mathrm{G}^{2} \mathrm{CS} 2\right.$ vs $\mathrm{G}^{2} \mathrm{CS} 3$ and $\mathrm{G}^{2} \mathrm{CS} 1$ vs $\mathrm{G}^{2} \mathrm{CS} 2$; stimulus $\times$ condition, $\mathrm{F}_{1,28}=4.51, \quad p<0.05, \quad \eta_{\mathrm{p}}^{2}=0.14 ; \quad$ stimulus $\times$ condition, $\mathrm{F}_{1,28}=7.21, p<0.05, \eta_{\mathrm{p}}^{2}=0.21$, respectively). That is, we observed a significant generalization of the startle fear response to the word cue of the non-reactivated CS2 in the yohimbine condition $\left(\mathrm{G}^{2} \mathrm{CS} 2\right.$ vs $\mathrm{G}^{2} \mathrm{CS} 3$ and $\mathrm{G}^{2} \mathrm{CS} 1$ vs $\mathrm{G}^{2} \mathrm{CS} 2$; stimulus, $\quad \mathrm{F}_{1,14}=22.59, \quad p<0.001, \quad \eta_{\mathrm{p}}^{2}=0.62$; $\quad$ stimulus, $\mathrm{F}_{1,14}=46.86, p<0.001, \eta_{\mathrm{p}}^{2}=0.77$, respectively) but not in the placebo pill group (stimulus, $\mathrm{F}_{1,14}<3.19$ ). Hence, the yohimbine $\mathrm{HCl}$ manipulation triggered fear generalization to the more abstract word stimulus. The word cue of the reactivated CS1 did not uncover any fear response in both the yohimbine and placebo pill condition $\left(\mathrm{G}^{2} \mathrm{CS} 1\right.$ vs $\mathrm{G}^{2} \mathrm{CS} 3$; stimulus, $\left.\mathrm{F}_{1,28}<1\right)$. Taken together, these findings demonstrate that the administration of yohimbine $\mathrm{HCl}$ during acquisition resulted in a broader generalization of fear $48 \mathrm{~h}$ later, while this generalization effect was eliminated by the administration of propranolol $\mathrm{HCl}$ during memory reactivation.

Analysis of the startle response to NA showed no significant differences between the two conditions during acquisition and extinction learning (condition, $\mathrm{F}_{1,28}<2.85$ ) nor during memory reactivation, reinstatement testing, and generalization $\left(t_{28}<1.47\right)$.

Skin conductance responding. Overall analysis of electrodermal responding revealed no fear conditioning during acquisition ( $\mathrm{CS} 1_{\text {Spider }}$ vs $\mathrm{CS} 3_{\mathrm{Mug}}-\mathrm{CS} 2_{\mathrm{Gun}}$ vs $\mathrm{CS} 3_{\mathrm{Mug}}$ ) (stimulus $\times$ trial, $\left.\mathrm{F}_{1,28}<1\right)$. When fear responses are not successfully acquired, one cannot assess the return of fear. Therefore, only subjects showing successful levels of fear acquisition (ie, trial 5 CS1 or CS2 $>$ CS3) were included in the analyses. Five subjects were eliminated. That is, two subjects from the yohimbine condition and three subjects from the placebo pill group.

Subsequent analyses of variance showed no effects of the yohimbine $\mathrm{HCl}$ and propranolol $\mathrm{HCl}$ manipulation on skin conductance responding. We observed a significant increase in electrodermal activity during acquisition (trial $1 v s$ trial 5 - day 1) in both conditions (CS1 vs CS3, CS2 vs CS3; stimulus $\times$ trial, $\quad \mathrm{F}_{1,23}=11.51, \quad p<0.01, \quad \eta_{\mathrm{p}}^{2}=0.33 ; \quad \mathrm{F}_{1,23}=$ 7.53, $\quad p<0.05, \quad \eta_{\mathrm{p}}^{2}=0.25, \quad$ respectively; stimulus $\times$ trial $\times$ condition, $\mathrm{F}_{1,23}<1$; Figure $3 \mathrm{a}$ and $\mathrm{b}$ ). Furthermore, the two groups showed similar levels of electrodermal responding during the reactivation trial on day 2 (CS1-R; $\left.t_{23}<1\right)$. Moreover, in both the yohimbine and placebo pill group, the differential skin conductance response (CS1 vs CS3, CS2 vs CS3) obtained during acquisition (ie, trial 5 - day 1) remained stable $48 \mathrm{~h}$ later (ie, trial 1 - day 3 ) (stimulus $\times$ trial, stimulus $\times$ trial $\times$ condition, $\mathrm{F}_{1,23}<1.52$ ). In both groups, a significant decrease in electrodermal responding was observed during extinction learning (trial 1 vs trial 10 - day 3) (CS1 vs CS3, CS2 vs CS3; stimulus $\times$ trial, $\mathrm{F}_{1,23}=11.83, p<0.01, \eta_{\mathrm{p}}^{2}=0.34 ; \mathrm{F}_{1,23}=11.03, p<0.01, \eta_{\mathrm{p}}^{2}=$ 0.32 , respectively; stimulus $\times$ trial $\times$ condition, $\mathrm{F}_{1,23}<1$ ). Analysis of the reinstatement effect further revealed a recovery in electrodermal responding from the last trial of extinction to the first trial at test in the yohimbine as well as placebo pill condition (CS1 vs CS3, CS2 vs CS3; stimulus $\times$ trial, $\mathrm{F}_{1,23}=4.77, p<0.05, \eta_{\mathrm{p}}^{2}=0.17 ; \mathrm{F}_{1,23}=4.35, p<0.05$, $\eta_{\mathrm{p}}^{2}=0.16$, respectively; stimulus $\times$ trial $\times$ condition, $\mathrm{F}_{1,23}<1$ ). In addition, the two groups showed a generalization of the skin conductance response to the category-related picture $\left(\mathrm{G}_{\mathrm{p}} \mathrm{CS} 1\right.$ vs $\mathrm{G}_{\mathrm{p}} \mathrm{CS} 3, \mathrm{G}_{\mathrm{p}} \mathrm{CS} 2$ vs $\mathrm{G}_{\mathrm{p}} \mathrm{CS} 3$; main effect of stimulus, $\mathrm{F}_{1,23}=5.31$, $p<0.05, \eta_{\mathrm{p}}^{2}=0.19 ; \mathrm{F}_{1,23}=4.81, p<0.05, \eta_{\mathrm{p}}^{2}=0.17$, respectively; stimulus $\times$ condition, $\left.\mathrm{F}_{1,23}<1\right)$ as well as word cue $\left(\mathrm{G}_{\mathrm{w}} \mathrm{CS} 1\right.$ vs $\mathrm{G}_{\mathrm{w}} \mathrm{CS} 3, \mathrm{G}_{\mathrm{w}} \mathrm{CS} 2$ vs $\mathrm{G}_{\mathrm{w}} \mathrm{CS} 3$; main effect of stimulus, $\mathrm{F}_{1,23}=5.08$, $p<0.05, \eta_{\mathrm{p}}^{2}=0.17 ; \mathrm{F}_{1,23}=5.56, p<0.05, \eta_{\mathrm{p}}^{2}=0.20$, respectively; stimulus $\times$ condition, $\mathrm{F}_{1,23}<1$ ). Note that analyses over the entire sample also revealed no differences between the yohimbine and placebo pill condition (CS1 vs CS3, CS2 vs CS3; stimulus $\times$ trial $\times$ condition, $\left.\mathrm{F}_{1,28}<1.07\right)$.

Retrospective US expectancy ratings. ANOVA revealed no effects of either drug manipulations on the retrospective US expectancy ratings. In both the yohimbine and placebo pill group, we observed a significant differential increase in expectancy ratings during acquisition (trial 1 vs trial 5; day 1) (CS1 vs CS3, CS2 vs CS3; stimulus $\times$ trial, $\mathrm{F}_{1,28}=405.18$, $p<0.001, \quad \eta_{\mathrm{p}}^{2}=0.94 ; \quad \mathrm{F}_{1,28}=547.74, \quad p<0.001, \quad \eta_{\mathrm{p}}^{2}=0.95$, respectively; stimulus $\times$ trial $\times$ condition, $\mathrm{F}_{1,28}<1.23$; see Supplementary Figure S2a and b). Furthermore, the two groups did not differ in their US expectancy during memory reactivation (day 2$)\left(\mathrm{CS} 1-\mathrm{R} ; t_{28}<1\right)$. Moreover, in both the yohimbine and placebo pill condition, the expectancy ratings remained stable from the last acquisition trial (day 1 ) to the first extinction trial $48 \mathrm{~h}$ later (day 3 ) (stimulus $\times$ trial, stimulus $\times$ trial $\times$ condition, $\mathrm{F}_{1,28}<1.84$ ). ANOVA showed extinction learning on day 3 by a significant differential decrease in US expectancy from the first extinction trial to the last trial of extinction learning in both conditions (CS1 vs CS3, CS2 vs CS3; stimulus $\times$ trial, $\mathrm{F}_{1,28}=208.45, p<0.001, \eta_{\mathrm{p}}^{2}=0.88 ; \mathrm{F}_{1,28}=165.67, p<0.001$, $\eta_{\mathrm{p}}^{2}=0.86$, respectively; stimulus $\times$ trial $\times$ condition, $\left.\mathrm{F}_{1,28}<1.56\right)$. We further observed a significant reinstatement effect from the last trial of extinction to the first trial at test in the yohimbine as well as placebo pill group (CS1 vs CS3, CS2 vs CS3, stimulus $\times$ trial, $\mathrm{F}_{1,28}=107.67, p<0.001$, $\eta_{\mathrm{p}}^{2}=0.79 ; \quad \mathrm{F}_{1,28}=89.90, p<0.001, \eta_{\mathrm{p}}^{2}=0.76$, respectively; 
a
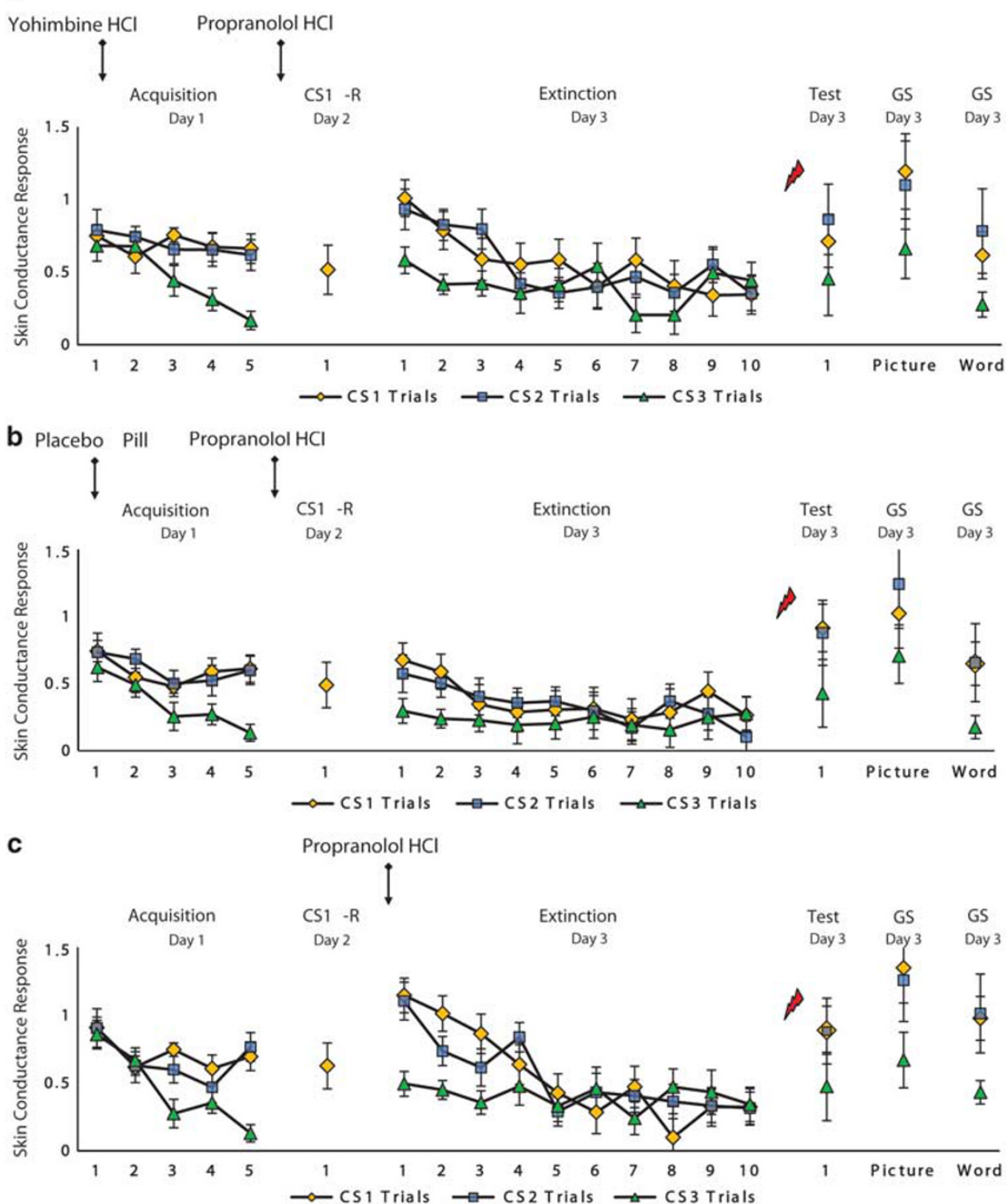

Figure 3 Mean skin conductance responses to the CSI, CS2, and CS3 trials during acquisition, memory reactivation, extinction, test, and generalization for the (a) yohimbine $\mathrm{HCl}$-propranolol $\mathrm{HCl}$ and (b) placebo pill-propranolol $\mathrm{HCl}$ condition (ie, Experiment I), and the (c) propranolol $\mathrm{HCl}$ after reactivation group (ie, Experiment II). Error bars represent SEM.

stimulus $\times$ trial $\times$ condition, $\left.\mathrm{F}_{1.28}<1.21\right)$. Moreover, in both groups, we observed a generalization of the US expectancy ratings to the category-related picture $\left(\mathrm{G}_{\mathrm{p}} \mathrm{CS} 1\right.$ vs $\mathrm{G}_{\mathrm{p}} \mathrm{CS} 3$, $\mathrm{G}_{\mathrm{p}} \mathrm{CS} 2$ vs $\mathrm{G}_{\mathrm{p}} \mathrm{CS} 3$; main effect of stimulus, $\mathrm{F}_{1,28}=142.73$, $p<0.001, \quad \eta_{\mathrm{p}}^{2}=0.84 ; \quad \mathrm{F}_{1,28}=137.87, \quad p<0.001, \quad \eta_{\mathrm{p}}^{2}=0.83$, respectively; stimulus $\times$ condition, $\left.\mathrm{F}_{1,28}<1.45\right)$ as well as word cue $\left(\mathrm{G}_{\mathrm{w}} \mathrm{CS} 1 v s \mathrm{G}_{\mathrm{w}} \mathrm{CS} 3, \mathrm{G}_{\mathrm{w}} \mathrm{CS} 2\right.$ vs $\mathrm{G}_{\mathrm{w}} \mathrm{CS} 3$; main effect of stimulus, $\mathrm{F}_{1,28}=138.07, p<0.001, \eta_{\mathrm{p}}^{2}=0.83 ; \mathrm{F}_{1,28}=140.63$, $p<0.001, \quad \eta_{\mathrm{p}}^{2}=0.83$, respectively; stimulus $\times$ condition, $\mathrm{F}_{1,28}<1.12$ ).

\section{Experiment II, Propranolol after Reactivation}

To rule out the effect of the propranolol $\mathrm{HCl}$ manipulation on the retrieval of the fear memory itself, participants in Experiment II received an oral dose of propranolol $\mathrm{HCl}$ directly after reactivation. Resembling our previous findings (Kindt et al, 2009; Soeter and Kindt, 2010, 2011a), the administration of pills following memory reactivation also selectively eliminated the startle fear response $48 \mathrm{~h}$ after fear acquisition (CS1 vs CS3; stimulus $\times$ trial, $\mathrm{F}_{1,9}=12.11$, $p<0.01, \quad \eta_{\mathrm{p}}^{2}=0.57$; Figure 2c), without affecting skin conductance discrimination and the retrospective US expectancy ratings (Figure 3c; see also Supplementary Results and Supplementary Figure S2c).

\section{DISCUSSION}

The present findings demonstrate that stimulation of the noradrenergic system during memory formation delayed the process of fear extinction without impairing the 
disruption of reconsolidation (ie, startle fear responding). The competition between the original excitatory fear association and the newly formed inhibitory memory trace determines the behavioral outcome of extinction learning (Myers and Davis, 2002). Given that yohimbine $\mathrm{HCl}$ was administered during fear acquisition - and not during fear extinction $48 \mathrm{~h}$ later-the $\alpha_{2}$-adrenergic drug apparently delayed the process of extinction by strengthening the original excitatory fear association (Soeter and Kindt, $2011 b)$. Yet, the yohimbine $\mathrm{HCl}$ manipulation did not directly augment the differential startle fear responding either 24 or $48 \mathrm{~h}$ after fear learning. That is, in both the placebo pill and yohimbine $\mathrm{HCl}$ group, the fear responding obtained during acquisition (day 1) remained stable during memory reactivation (day 2 - reactivated fear association) as well as retention testing $48 \mathrm{~h}$ later (non-reactivated fear association). Our finding that yohimbine $\mathrm{HCl}$ strengthened the original fear association without directly augmenting its behavioral expression may suggest a ceiling effect in startle fear conditioning (day 1) (see also, Soeter and Kindt, 2011b). Note that the $\beta$-blocker (propranolol $\mathrm{HCl}$ ) during memory retrieval (day 2) may also have suppressed a potential fear-enhancing effect of the yohimbine $\mathrm{HCl}$ manipulation (day 1). In any case, whereas the $\alpha_{2^{-}}$ adrenergic drug delayed the process of extinction learning and triggered broader fear generalization $48 \mathrm{~h}$ later, the $\beta$-adrenergic receptor blocker (ie, propranolol $\mathrm{HCl}$ ) during reconsolidation (day 2) selectively diminished the startle fear responding to the reactivated fear association along with its category-related information (day 3). Moreover, we observed a similar reduction in startle fear responding when the $\beta$-adrenergic receptor antagonist was administered after reactivation of the memory (ie, Experiment II), suggesting that the propranolol $\mathrm{HCl}$ manipulation before reactivation also affected the processes mediating reconsolidation (ie, Experiment I) (Nader et al, 2000). The present study employed stimuli of different 'valence' categories (fearrelevant $v s$ fear-irrelevant) to verify whether the propranolol $\mathrm{HCl}$ manipulation was capable of neutralizing fear responding. That is, since fear-relevant stimuli are known to have an innate prepotency to elicit fear responses (Lovibond et al, 1994), we employed a fear-irrelevant cue as an additional control stimulus. The downside of this procedure is that the differential responding observed during acquisition (day 1) may simply be due to the emotional 'valence' of the stimuli employed (fear-relevant $v s$ fear-irrelevant) rather than associative learning. Previously, we demonstrated in a fear conditioning paradigm that fear relevancy does not affect fear responding in the absence of associative learning (ie, first acquisition trial; Soeter and Kindt, 2011a). Again, we did not observe any difference in fear responding to the first trial of acquisition, indicating that the differential fear responding observed at the end of fear conditioning (day 1) was due to associative learning instead of the 'valence' of the cues. Thus, taken together, given that we observed a similar level of startle fear responding to the reactivated fear association and the fear-irrelevant control stimulus at retention testing (day 3 ), the $\beta$-adrenergic receptor blocker during reconsolidation apparently 'neutralized' the fear-arousing aspects of the 'associative' fear memory along with its category-related information (ie, generalization testing).
In line with our preceding studies, the $\alpha_{2}$-adrenergic (Soeter and Kindt, 2011b) as well as $\beta$-adrenergic drug (Kindt et al, 2009; Soeter and Kindt, 2010, 2011b) did not affect the skin conductance responding and retrospective US expectancy ratings. Considering that online ratings direct the attention towards the CS-US relation (Baeyens et al, 1990; Lovibond and Shanks, 2002) and skin conductance responding is highly sensitive to attentional processes (Filion et al, 1991), the use of online ratings may previously have interfered with the measurement of electrodermal activity (Soeter and Kindt, 2010, 2011a,b). The current observation that the omission of online ratings does not differentially affect skin conductance responding corresponds to the view that electrodermal activity may primarily reflect the more cognitive level of contingency learning (ie, declarative knowledge) (Weike et al, 2007; but see, Schultz and Helmstetter, 2010). Studying human fear conditioning allows for the independent evaluation of both declarative knowledge and the fear response. In most fear conditioning studies, the conscious anticipation of an aversive stimulus (US) is associated with an increase in startle potentiation (Grillon and Davis, 1995; Lovibond and Shanks, 2002). However, there are also several observations showing that unawareness of a CS-US contingency does not preclude a startle fear response (eg, Weike et al, 2007). This indicates that the anticipation of an aversive stimulus is not a necessary condition to observe fear-potentiated startle responses. Our findings show that the anticipation of an US is also not a sufficient condition to generate fear-potentiated startle responses. As such, our results emphasize the concept of multiple memory systems and suggest a double dissociation between the emotional and cognitive representation of fear (Squire, 2005; LaBar and Cabeza, 2006; Weike et al, 2005, 2007). It should be noted that these findings do not imply that reconsolidation is restricted to the emotional expression of fear memory (ie, startle fear responding). In view of the hypothesized adaptive function of memory reconsolidation (Dudai, 2006, 2009; Lee, 2009), there is no a priori reason for assuming that some memory systems would not be sensitive to disrupting reconsolidation (Lee, 2009).

In our previous work (Kindt et al, 2009; Soeter and Kindt, 2010), the erasure of the fear response could also have resulted from a more diffuse effect of the propranolol $\mathrm{HCl}$ manipulation by reducing the fear-provoking aspects of the aversive consequence itself (US). In considering clinical implications, disrupting reconsolidation should not radically alter functional reactions to potentially dangerous situations (US), but selectively weaken the underlying maladaptive fear association (CS1-US). Our current observation that the non-reactivated stimulus (CS2) potentiated the startle fear responding at test (day 3 ) indicates that the participants still feared the US, but no longer the reactivated conditioned stimulus (CS1) (see also, Soeter and Kindt, 2011a). Apparently, the propranolol $\mathrm{HCl}$ manipulation selectively disrupted the CS1-US association at the emotional level given that the participants also expected the US when presented with the reactivated stimulus (CS1) at test (day 3). Taken together, these findings show that there is no causal link between the 'actual knowledge' of a fear association and its fear response, even though they often operate in parallel. Note that the fear-erasing effects were 
not restricted to the feared cue itself (CS1), but instead generalized to category-related information not previously associated with the originally feared stimulus. The generalization of fear has been demonstrated to be dependent on the training-induced strength of the memory (Laxmi et al, 2003). Here, the strengthening of the fear memory trace by the $\alpha_{2}$-adrenergic manipulation indeed triggered broader fear generalization (category-related word cues). Conversely, the $\beta$-adrenergic interference with reconsolidation left the memory trace too weak to yield a generalized fear response (Soeter and Kindt, 2011a). Several findings have implicated CREB phosphorylation in the formation (Josselyn et al, 2001; Davies et al, 2004) as well as generalization of fear memory (Han et al, 2008). Whereas yohimbine $\mathrm{HCl}$ is known to induce $p$ CREB activation (Sun et al, 2010), the $\beta$ adrenergic receptor antagonist propranolol has been shown to inhibit noradrenaline-stimulated CREB phosphorylation (Thonberg et al, 2002). The present findings show the involvement of noradrenergic modulation in the generalization of human associative fear memory. Corroborating our previous study, the findings further demonstrate that the assimilation of individual memory items into a generalized schema may be dissociable for semantic and affective knowledge (Soeter and Kindt, 2011a). That is, upon exposure to the category-related information of the reactivated fear memory, the participants again predicted danger without a concomitant fear response.

While fear responses are very common in the aftermath of a traumatic event, the intensity of this initial fear responding is generally a poor indicator of symptom development or PTSD diagnosis (Rothbaum et al, 1992; Brewin et al, 2000; Murray et al, 2002). Rather, the impairment in the 'unlearning' of fear-related behavior as well as the generalization of fear to intrinsically safe stimuli (Blechert et al, 2007; Lissek and Grillon, 2010) has a strong relevance to the development of anxiety disorders such as PTSD. Hence, our data indicate that the noradrenaline level during or shortly after a traumatic experience may contribute to the etiology of post-traumatic stress disorder. At the same time, the present findings may have valuable therapeutic implications given that the strength of the fear memory did not act as a constraint on reconsolidation. It may be possible that the stimulation of the noradrenergic system during memory formation was not strong enough to prevent the disruption of reconsolidation (Suzuki et al, 2004; Wang et al, 2009). On the other hand, the yohimbine $\mathrm{HCl}$ manipulation yielded a resistance to fear extinction $48 \mathrm{~h}$ later and triggered broader fear generalization, indicating the former strengthening of the excitatory fear memory (Myers and Davis, 2002; Soeter and Kindt, 2011b). Moreover, preliminary evidence in trauma patients also revealed diminished trauma-relevant physiological responding following the $\beta$-adrenergic interference with reconsolidation (Brunet et al, 2008). The current observation that propranolol $\mathrm{HCl}$ can well be administered after reactivation of the fear memory (ie, Experiment II) further has implications in light of the demarcation between 'extinction' and 'reconsolidation' (Eisenberg et al, 2003; Pedreira and Maldonado, 2003; Suzuki et al, 2004). That is, when memory retrieval initiates extinction learning instead of reconsolidation, the propranolol $\mathrm{HCl}$ manipulation should be omitted to avoid interference with the consolidation of extinction training (Ouyang and Thomas, 2005; Mueller et al, 2008).

The 'process of extinction' and 'disrupting reconsolidation' are two approaches to diminish fear-related behavior. The extinction of fear not only leaves the original fear memory intact - thereby explaining the return of fear after apparently successful fear reduction (Bouton, 1993) - but may also be impaired by noradrenergic stimulation during the formation of the excitatory fear memory. Conversely, $\beta$ adrenergic receptor blockade during reconsolidation selectively 'deletes' the fear-arousing aspect of noradrenergic strengthened fear memory and-on top of that - undermines the generalization of fear responding. Given that fear generalization lies at the heart of many anxiety disorders, disrupting reconsolidation points to a promising strategy in reducing excessive fear responding.

\section{ACKNOWLEDGEMENTS}

We thank B Molenkamp for technical assistance. This work was supported by a Vici grant (Merel Kindt) from the Netherlands Organization for Scientific Research.

\section{DISCLOSURE}

The authors declare no conflict of interest.

\section{REFERENCES}

Baeyens F, Eelen P, van den Berg O (1990). Contingency awareness in evaluative conditioning: a case for unaware affectiveevaluative learning. Cogn Emot 4: 3-18.

Blechert J, Michael T, Vriends N, Margraf J, Wilhelm FH (2007). Fear conditioning in posttraumatic stress disorder: evidence for delayed extinction of autonomic, experiential, and behavioural responses. Behav Res Ther 45: 2019-2033.

Bouton ME (1993). Context, time, and memory retrieval in the interference paradigm of Pavlovian learning. Psychol Bull 114: 80-99.

Brewin CR, Andrews B, Valentine JD (2000). Meta-analysis of risk factors for posttraumatic stress disorder in trauma-exposed adults. J Cons Clin Psychol 68: 748-766.

Brunet A, Orr SP, Tremblay J, Robertson K, Nader K, Pitman RK (2008). Effect of post-retrieval propranolol on psychophysiological responding during subsequent script-driven traumatic imagery in post-traumatic stress disorder. J Psych Res 42: 503-506.

Charney DS, Woods SW, Goodam WK, Heninger GR (1987). Neurobiological mechanisms of panic-anxiety: biochemical and behavioral correlates of yohimbine-induced panic attacks. Am J Psych 44: 1030-1036.

Davies MF, Tsui J, Flannery JA, Li X, DeLorey TM, Hoffman BB (2004). Activation of $\alpha_{2}$ adrenergic receptors suppresses fear conditioning: expression of c-Fos and phosphorylated CREB in mouse amygdala. Neuropsychopharmacology 29: 229-239.

Davis M, Falls WA, Campeau S, Kim M (1993). Fear-potentiated startle: a neural and pharmacological analysis. Behav Brain Res 58: $175-198$.

Debiec J, LeDoux JE (2004). Disruption of reconsolidation but not consolidation of auditory fear conditioning by noradrenergic blockade in the amygdala. Neuroscience 129: 267-272.

Dudai Y (2006). Reconsolidation: the advantage of being refocused. Curr Opin Neurobiol 16: 174-178. 
Dudai Y (2009). Predicting not to predict too much: how the cellular machinery of memory anticipates the uncertain future. Philoso Trans $R$ Soc B 364: 1255-1262.

Eisenberg M, Kobilo T, Berman DE, Dudai Y (2003). Stability of retrieved memory: inverse correlation with trace dominance. Science 301: 1102-1104.

Filion DL, Dawson ME, Schell AM, Hazlett EA (1991). The relationship between skin conductance orienting and the allocation of processing resources. Psychophysiology 28: 410-424.

Gilman AG, Goodman LS (1996). Goodman and Gilman's the Pharmacological Basis of Therapeutics. McGraw-Hill: New York, NY.

Grasing K, Sturgill MG, Rosen RC, Trout JR, Thomas TJ, Kulkarni GD et al. (1996). Effects of yohimbine on autonomic measures are determined by individual valued for area under the concentration-time curve. J Clin Pharmacol 36: 814-822.

Grillon C, Cordova J, Morgan CA, Chaney DS, Davis M (2004). Effects of the beta-blocker propranolol on cued and contextual fear conditioning in humans. Psychopharmacology 175: 342-352.

Grillon C, Davis M (1995). Acoustic startle and anticipatory anxiety in humans: effects of monaural right and left ear stimulation. Psychophysiology 32: 155-161.

Hamm AO, Weike AI (2005). The neuropsychology of fear learning and fear regulation. Int J Psychophysiol 57: 5-14.

Han J-H, Yiu AP, Cole CJ, Hsiang H-L, Neve RL, Josselyn SA (2008). Increasing CREB in the auditory thalamus enhances memory and generalization of auditory conditioned fear. Learn Mem 15: 443-453.

Josselyn SA, Chanjun S, Carlezon Jr WA, Neve RL, Nestler EJ, Davis M (2001). Long-term memory is facilitated by cAMP response element-binding protein overexpression in the amygdala. J Neurosci 21: 2404-2412.

Kindt M, Soeter M, Vervliet B (2009). Beyond extinction: erasing human fear responses and preventing the return of fear. Nat Neurosci 12: 256-258.

Klorman R, Weerts TC, Hastings JE, Melamed GBG, Lang PJ (1974). Psychometric description of some specific fear questionnaires. Behav Ther 5: 401-409.

LaBar KS, Cabeza R (2006). Cognitive neuroscience of emotional memory. Nat Rev 7: 54-64.

LaBar KS, Gatenby JC, Gore JC, LeDoux JE, Phelps EA (1998). Human amygdala activation during conditioned fear acquisition and extinction: a mixed-trial fMRI study. Neuron 20: 937-945.

Lang PJ, Bradley MM, Cuthbert BM (2005). International Affective Picture System (IAPS): Affective Ratings of Pictures and Instruction Manual. University of Florida: Gainesville, FL.

Laxmi TR, Stork O, Pape HC (2003). Generalisation of conditioned fear and its behavioural expression in mice. Behav Brain Res 145: $89-98$.

Lee JLC (2009). Reconsolidation: maintaining memory relevance. Trends Neurosci 32: 413-420.

Lissek S, Biggs AL, Rabin SJ, Cornwell BR, Alvarez RP, Pine DS et al. (2008). Generalization of conditioned fear-potentiated startle in humans: experimental validation and clinical relevance. Behav Res Ther 46: 678-687.

Lissek S, Grillon C (2010). Overgeneralization of conditioned fear in the anxiety disorders. J Psychol 218: 146-148.

Lovibond PF, Hanna SK, Siddle DAT, Bond NW (1994). Electrodermal and subjective reactions to fear-relevant stimuli under threat of shock. Aus J Psychol 46: 73-80.

Lovibond PF, Shanks DR (2002). The role of awareness in Pavlovian conditioning: empirical evidence and theoretical implications. J Exp Psychol 28: 3-26.

McGaugh ML, Roozendaal B (2009). Drug enhancement of memory consolidation: historical perspective and neurobiological implications. Psychopharmacology 202: 1-14.
Mineka S, Öhman A (2002). Phobias and preparedness: the selective, automatic, and encapsulated nature of fear. Biol Psych 52: 927-937.

Mueller D, Porter JT, Quirk GJ (2008). Noradrenergic signaling in infralimbic cortex increases cell excitability and strengthens memory for fear extinction. J Neurosci 28: 369-375.

Murray J, Ehlers A, Mayou RA (2002). Dissociation and posttraumatic stress disorder: two prospective studies of road accident survivors. Br J Psych 180: 363-368.

Myers KM, Davis M (2002). Behavioral and neural analysis of extinction. Neuron 36: 722-726.

Nader K, Schafe GE, LeDoux JE (2000). Fear memories require protein synthesis in the amygdala for reconsolidation after retrieval. Nature 406: 722-726.

Norrholm SD, Jovanovic T, Vervliet B, Myers K, Davis M, Rothbaum BO et al. (2006). Conditioned fear extinction and reinstatement in a human fear potentiated startle paradigm. Learn Mem 13: 681-685.

Ouyang M, Thomas SA (2005). A requirement for memory retrieval during and after long-term extinction learning. Proc Natl Acad Sci USA 102: 9347-9352.

Pedreira ME, Maldonado H (2003). Protein synthesis subserves reconsolidation or extinction depending on reminder duration. Neuron 38: 863-869.

Peskind ER, Wingerson D, Murray S, Pascualy M, Dobie DJ, Le Corre P et al. (1995). Effects of Alzheimer's disease and normal aging on cerebrospinal fluid norepinephrine responses to yohimbine and clonidine. Arch Gen Psych 52: 774-782.

Peterson RA, Reiss S (1992). Anxiety Sensitivity Index Manual. International Diagnostic System: Worthington, OH.

Rothbaum BO, Foa EB, Riggs DS, Murdock T, Walsh W (1992). A prospective examination of post-traumatic stress disorder in rape victims. J Traum Stress 5: 455-475.

Schultz DH, Helmstetter FJ (2010). Classical conditioning of autonomic fear responses is independent of contingency awareness. J Exp Psychol 36: 495-500.

Soeter M, Kindt M (2010). Dissociating response systems: erasing fear from memory. Neurobiol Learn Mem 94: 30-41.

Soeter M, Kindt M (2011a). Disrupting reconsolidation: pharmacological and behavioral manipulations. Learn Mem 18: 357-366.

Soeter M, Kindt M (2011b). Noradrenergic enhancement of associative fear memory in humans. Neurobiol Learn Mem 96: 263-271.

Spielberger CD, Gorsuch RL, Lusthene RE (1970). Manual for the State-Trait Anxiety Inventory. Consulting Psychologists Press: Palo Alto, CA.

Squire LR (2005). Memory systems of the brain: a brief history and current perspective. Neurobiol Learn Mem 82: 171-177.

Stegeren AH, Rohleder B, Everaerd W, Wolf OT (2006). Salivary alpha amylase as marker for adrenergic activity during stress: effect of beta blockade. Psychoneuroendocrinology 31: 137-141.

Stegeren AH, Roozendaal B, Kindt M, Wolf OT, Joëls M (2009). Interacting noradrenergic and corticosteroid systems shift human brain activation patterns during encoding. Neurobiol Learn Mem 93: 56-65.

Sun HS, Green TA, Theobald DEH, Laali S, Shrikhande G, Birnbaum S et al. (2010). The pharmacological stressor yohimbine increases impulsivity through activation of CREB in the orbitofrontal cortex. Biol Psych 67: 649-656.

Suzuki A, Josselyn SA, Frankland PW, Masushige S, Silva AJ, Kida S (2004). Memory reconsolidation and extinction have distinct temporal and biochemical signatures. J Neurosci 24: 4787-4795.

Thonberg H, Fredriksson JM, Nedergaard J, Cannon B (2002). A novel pathway for adrenergic stimulation of cAMP-responseelement-binding protein (CREB) phosphorylation: mediation via $\alpha_{1}$-adrenoceptors and protein kinase $C$ activation. Biochem J 264: $73-79$. 
Wang S-H, Oliveira Alvares L, Nader K (2009). Cellular and systems mechanism of memory strength as a constraint on auditory fear reconsolidation. Nat Neurosci 12: 906-913.

Weike AI, Hamm AO, Schupp HT, Runge U, Schroeder HWS, Kessler C (2005). Fear conditioning following unilateral temporal lobectomy: dissociation of conditioned startle potentiation and autonomic learning. J Neurosci 25: 11117-11124.

Weike AI, Schupp HT, Hamm AO (2007). Fear acquisition requires awareness in trace but not delay conditioning. Psychophysiology 44: $170-180$.

Supplementary Information accompanies the paper on the Neuropsychopharmacology website (http://www.nature.com/npp) 